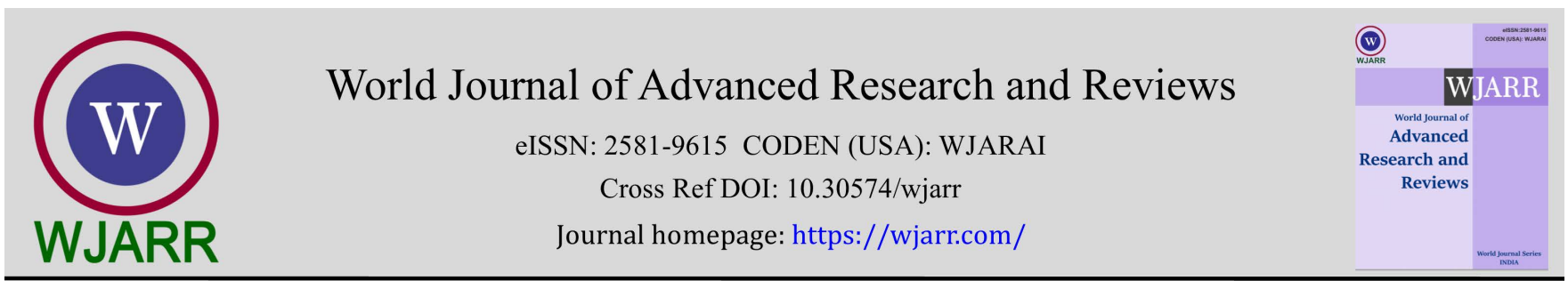

(RESEARCH ARTiClE)

\title{
Effect of variation in air conditioner temperature on peak expiratory flow rate of air conditioner users
}

\author{
Swarnali Chakrabarty*, Qazi Shamima Akhter, Lala Shourav Das and Mohammad Mostafizur Rahman \\ Department of Physiology, Dhaka medical college, Dhaka, Bangladesh.
}

World Journal of Advanced Research and Reviews, 2021, 11(01), 151-156

Publication history: Received on 15 June 2021; revised on 16 July 2021; accepted on 20 July 2021

Article DOI: https://doi.org/10.30574/wjarr.2021.11.1.0330

\begin{abstract}
As a result of increasing environmental temperature, use of air conditioner (AC) has become very popular specially in the urban areas mostly during warmer months of the year. Exposure to cold, dry air of AC on a regular basis can cause various alternations in lung functions of AC users which can lead to many future lung diseases. These alternations in lung functions can be influenced by the temperature at which AC is regulated. This cross-sectional study was conducted to observe the effects of air conditioner use and variation of AC temperature on peak expiratory flow rate (PEFR) of apparently healthy adult male and female living in Dhaka city, Bangladesh. The study group (group A) consisted of 48 apparently healthy adult male and female who were exposed to air conditioner for at least 6 hours per day for minimum 5 days per week for the past 2 to 4 years. They were divided into two subgroups based on temperature at which AC was regulated. Group $A_{1}$ consisted of 24 subjects ( 12 male and 12 female) who were exposed to AC for at least 6 hours per day for minimum 5 days per week for the past 2 to 4 years and where temperature of the AC was constantly regulated in between $18^{\circ} \mathrm{C}$ to $22^{\circ} \mathrm{C}$. Group $\mathrm{A}_{2}$ consisted of 24 subjects ( 12 male and 12 female) who were exposed to AC for the same period of time but where $\mathrm{AC}$ was constantly regulated in between $23^{\circ} \mathrm{C}$ to $25^{\circ} \mathrm{C}$. The control group (group $\mathrm{B}$ ) consisted of similar number of age, gender, BMI and socioeconomically matched subjects who did not use air conditioner nearly at all. Actual, predicted and percentage of predicted value of PEFR were estimated in both the study and control group using Minato Autospiro AS-507. Statistical analysis was done by unpaired Student's ' $\mathrm{t}$ ' test and $p$ value 0.05 was taken as level of significance. In this study mean actual and percentage (\%) of predicted value of PEFR were significantly lower in AC users in comparison to nonusers in case of both male and female. Between two groups of AC users, mean actual and percentage of predicted value of PEFR were significantly lower in the group where AC temperature was constantly regulated in between $18^{\circ} \mathrm{C}$ to $22^{\circ} \mathrm{C}$ in comparison to the group where $\mathrm{AC}$ temperature was constantly regulated in between $23^{\circ} \mathrm{C}$ to $25^{\circ} \mathrm{C}$. Use of $\mathrm{AC}$ can significantly reduce lung functions of $\mathrm{AC}$ users and lower $\mathrm{AC}$ temperature is associated with more reduction of PEFR in AC users.
\end{abstract}

Keywords: Air conditioner; AC temperature; Peak expiratory flow rate; Minato Autospiro AS-507

\section{Introduction}

Environmental temperature is increasing day by day as a consequence of increased industrial and infrastructural development, population overgrowth, excessive pollution etc. Dhaka, the capital city of Bangladesh is not an exception. Because of this trend of increasing environmental temperature, use of air conditioner (AC) has become very popular in urban areas like Dhaka city specially during warmer months of the year as the device can provide thermal comfort to people by cooling and dehumidifying the air [1,2]. This increasing use of AC in home, public transport, offices has now emerged as a new public health issue resulting from exposure of the airways to the cool, dry air of AC or more accurately from sudden temperature change. This sudden change of surrounding environmental temperature can affect the adaptive system of the AC users on long term $[3,4]$.

\footnotetext{
${ }^{*}$ Corresponding author: Swarnali Chakrabarty

Department of Physiology, Dhaka medical college, Dhaka, Bangladesh.

Copyright (C) 2021 Author(s) retain the copyright of this article. This article is published under the terms of the Creative Commons Attribution Liscense 4.0.
} 
Inhalation of cold, dry air of AC can lead to activation of nasal cold or osmoreceptors resulting in bronchoconstriction which serves as a protective response that limits the entry of cold and dry air into lungs. Furthermore, exposure to cold, dry air can also result in activation of vagal parasympathetic nerve, release of various inflammatory mediators from activated mast cells, injury and hyperresponsiveness of airway epithelium. There may be increased density of mite allergen and an enhanced risk of atopic sensitization in association with AC use. All these factors together can be responsible for alternation in lung functions of AC users. This alternation in lung functions in AC users may also depend on the temperature at which $\mathrm{AC}$ is regulated. Regulation of AC temperature at a lower level may result in more reduction of lung functions of $\mathrm{AC}$ users which can ultimately lead to many future lung diseases [5,6,3].

Lung function tests are group of tests that provide valuable information regarding respiratory system like condition of small and large airways, lung parenchyma, size and integrity of pulmonary capillary bed etc. Spirometry is a common, sensitive and noninvasive lung function test that can be performed almost anywhere because of its easy portability. There are three basic components of spirometry which are measurement of volume, time and flow of air. Among the various spirometric parameters, peak expiratory flow rate (PEFR) is one of the most important one which indicates the maximum flow rate achieved by the subject during the forced expiratory maneuver. It is useful in detecting presence and absence of lung diseases and effectiveness of medication $[1,7,8]$.

A previous study done on bank workers who were exposed to airconditioned work environment for 6 months to 5 years and where $\mathrm{AC}$ temperature was regulated in between $18^{\circ} \mathrm{C}$ to $22^{\circ} \mathrm{C}$, reported significant decrease in their PEFR value [9]. Another study showed significant reduction of PEFR value of AC users who were using AC for 5 to 6 hours in night and 2 to 3 hours per day for 12 to 15 months in comparison to nonusers [10].

On the other hand, another study showed no significant reduction in PEFR value in AC users who were using AC for at least 5 hours daily for the last 6 months in comparison to nonusers [8].

So, because of these conflicting results, the effects of air conditioner use on PEFR still remain questionable. Besides, gender wise comparison of PEFR was not done between the AC users and nonusers in most of these studies and no such study has yet been done on Bangladeshi people. Furthermore, it is almost impossible to completely stop use of AC in this twenty first century where environmental temperature is increasing day by day. A probable solution for this problem may be having knowledge about the range up to which AC temperature can be lowered and can be used safely without having harmful consequences on lung functions of AC users. With best of our knowledge no such study has yet been done on this issue. So, this study was conducted to evaluate the effects of AC use and variation in AC temperature on peak expiratory flow rate of AC users. This study can shade a new light on air conditioner use and create public awareness regarding this issue in near future.

\section{Material and methods}

This cross-sectional study was carried out after obtaining ethical clearance from research review committee and ethical review committee of Dhaka medical college, Dhaka. It was conducted in department of Physiology, Dhaka medical college from a period of July 2018 to June 2019. For this study 48 apparently health adult individuals (including 24 male and 24 female) who were exposed to airconditioned environment for minimum 6 hours per day for at least 5 days per weeks for the past 2 to 4 years were taken as study group (group A). They were divided into two subgroups based on temperature at which AC was regulated. Group $A_{1}$ consisted of 24 subjects (12 male and 12 female) who were exposed to $\mathrm{AC}$ for at least 6 hours per day for minimum 5 days per week for the past 2 to 4 years and where temperature of the $\mathrm{AC}$ was constantly regulated in between $18^{\circ} \mathrm{C}$ to $22^{\circ} \mathrm{C}$. Group $\mathrm{A}_{2}$ consisted of 24 subjects ( 12 male and 12 female) who were exposed to AC for the same period of time but where AC was constantly regulated in between $23^{\circ} \mathrm{C}$ to $25^{\circ} \mathrm{C}$. Similar number of age, gender, BMI and socioeconomically matched subjects who did not use AC nearly at all were taken as control group(group B). For the study group subjects were selected from employees working in intensive care unit of a specialized hospital and pharmaceutical laboratory of Pharmacy department of a private university. For the control group subjects were selected from administrative unit of a public university. All the subjects were nonsmoker, age ranging from 18 to 44 years, BMI ranging from 18.4 to $24.9 \mathrm{Kg} / \mathrm{m}^{2}$. All of them were free from COPD, asthma, pneumonia, tuberculosis, pleural effusion, hypertension, DM as per history. Subjects having symptoms suggestive of any respiratory or cardiac diseases, history of taking drugs like beta blocker, diuretics, cardiac glycosides, personal history of consumption of tobacco, betel nut, regular physical exercise, pregnancy, lactation were excluded from the study. After selection of the subjects, nature, purpose and benefits of the study were explained to the them and informed written consent was taken. After that procedure of spirometry was explained to them and they were allowed to perform some demonstrations to understand the procedure. Spirometry was done between 9 am to 12 pm to avoid any possible diurnal variation using Minato Autospiro AS-507 with all the subjects comfortably seated in an upright position. It was performed following a standardized procedure adherent to American Thoracic Society (ATS) guideline [11] under direct 
supervision of the principal researcher and ATS acceptability and repeatability criteria were followed to accept the best results. Subjects were allowed to perform a minimum 3 and a maximum of 8 tests and the best value of PEFR was selected. All the data were collected and recorded by the principal researcher in a prefixed data collection form. Statistical analysis was done by unpaired Student's ' $t$ ' test using computer based statistical program SPSS (Statistical Package for Social Science) version 25 and $p$ value $<0.05$ was taken as level of significance.

\section{Results and discussion}

In this study mean actual and \% of predicted value of PEFR were found to be significantly lower in the AC users (group A) in comparison to nonusers (group B) in case of both male and female, predicted value showed no significant difference (table 3,4). On comparison between two groups of AC users, actual and \% of predicted value of PEFR were significantly lower in the group $A_{1}$ in comparison to group $A_{2}$ (table 5,6) in case of both male and female but there was no significant difference in predicted value. Baseline characteristics such as age, BMI, systolic and diastolic blood pressure showed no significant difference in male and female subjects of study and control group (table 1 and table 2).

Table 1 General characteristics of male subjects in both groups

\begin{tabular}{|l|l|l|l|}
\hline Parameters & Group A $(\mathbf{n = 2 4 )}$ & Group B $(\mathbf{n = 2 6})$ & $\boldsymbol{p}$ value \\
\hline Age (years) & $37.36 \pm 8.56$ & $37.54 \pm 7.62$ & $0.713^{\text {ns }}$ \\
\hline BMI $\left(\mathrm{Kg} / \mathrm{m}^{2}\right)$ & $22.98 \pm 1.57$ & $23.06 \pm 1.33$ & $0.834^{\text {ns }}$ \\
\hline SBP $(\mathrm{mm} / \mathrm{Hg})$ & $109.79 \pm 7.56$ & $111.35 \pm 7.56$ & $0.487^{\mathrm{ns}}$ \\
\hline DBP $(\mathrm{mm} / \mathrm{Hg})$ & $76.87 \pm 5.48$ & $77.31 \pm 5.52$ & $0.782^{\text {ns }}$ \\
\hline
\end{tabular}

Data shown as mean \pm SD. Group $A=A C$ users, Group $B=A C$ non users, $B M I=$ Body mass index, $\mathrm{SBP}=$ Systolic blood pressure, $\mathrm{DBP}=$ Diastolic blood pressure

Table 2 General characteristics of female subjects in both groups

\begin{tabular}{|l|l|l|l|}
\hline Parameters & Group A(n=24) & Group B(n=22) & $\boldsymbol{p}$ value \\
\hline Age(years) & $31.20 \pm 8.39$ & $32.14 \pm 7.71$ & $0.699^{\mathrm{ns}}$ \\
\hline BMI $\left(\mathrm{Kg} / \mathrm{m}^{2}\right)$ & $22.76 \pm 1.85$ & $22.94 \pm 1.36$ & $0.713^{\text {ns }}$ \\
\hline SBP $(\mathrm{mm} / \mathrm{Hg})$ & $106.87 \pm 7.34$ & $110.23 \pm 7.63$ & $0.136^{\mathrm{ns}}$ \\
\hline DBP $(\mathrm{mm} / \mathrm{Hg})$ & $73.75 \pm 5.57$ & $75.91 \pm 5.03$ & $0.176^{\mathrm{ns}}$ \\
\hline
\end{tabular}

$\mathrm{SBP}=$ Systolic blood pressure, $\mathrm{DBP}=$ Diastolic blood pressure,ns=not significant

Table 3 Comparison of study parameters in male subjects of study and control group $\left(\mathrm{n}_{1}=50\right)$

\begin{tabular}{|l|c|c|c|}
\hline Parameters & $\begin{array}{c}\text { Group A } \\
\mathbf{n}_{\mathbf{1}} \mathbf{A}=\mathbf{2 4}\end{array}$ & $\begin{array}{c}\text { Group B } \\
\mathbf{n}_{\mathbf{1}} \mathrm{B}=\mathbf{2 6}\end{array}$ & $\boldsymbol{p}$ value \\
\hline PEFR & \multicolumn{3}{|l|}{} \\
\hline Actual value(L/S) & $4.64 \pm 0.95$ & $6.24 \pm 0.68$ & $<0.001^{\text {*** }}$ \\
\hline Predicted value(L/S) & $8.51 \pm 0.74$ & $8.73 \pm 0.75$ & $0.302^{\text {ns }}$ \\
\hline$\%$ Of predicted value & $54.58 \pm 9.29$ & $71.19 \pm 4.77$ & $<0.001^{* * *}$ \\
\hline
\end{tabular}


Table 4 Comparison of study parameters in female subjects of study and control group $\left(\mathrm{n}_{2}=46\right)$

\begin{tabular}{|c|c|c|c|}
\hline Parameters & $\begin{array}{l}\text { Group A } \\
\mathrm{n}_{2} \mathrm{~A}=24\end{array}$ & $\begin{array}{l}\text { Group B } \\
\mathrm{n}_{2} \mathrm{~B}=22\end{array}$ & $p$ value \\
\hline \multicolumn{4}{|l|}{ PEFR } \\
\hline Actual value(L/S) & $3.35 \pm 0.54$ & $4.32 \pm 0.65$ & $<0.001^{* * *}$ \\
\hline Predicted value(L/s) & $6.33 \pm 0.59$ & $6.59 \pm 0.44$ & $0.100^{\mathrm{ns}}$ \\
\hline$\%$ of predicted value & $52.96 \pm 7.89$ & $68.59 \pm 4.69$ & $<0.001^{* * *}$ \\
\hline
\end{tabular}

Table 5 Comparison of study parameters in male subjects of study group $\left(n_{1} A=24\right)$

\begin{tabular}{|l|l|l|l|}
\hline Parameters & $\begin{array}{l}\text { Group } A_{1} \\
\mathbf{n}_{1} \mathbf{A}_{\mathbf{1}}=12\end{array}$ & $\begin{array}{l}\text { Group } \mathbf{A}_{\mathbf{2}} \\
\mathbf{n}_{\mathbf{1}} \mathbf{A}_{\mathbf{2}}=\mathbf{1 2}\end{array}$ & $\boldsymbol{p}$ value \\
\hline PEFR & $4.19 \pm 0.50$ & $5.10 \pm 1.07$ & $<0.001^{* * *}$ \\
\hline Actual value(L/S) & $8.45 \pm 0.60$ & $8.56 \pm 0.85$ & $0.718^{\mathrm{ns}}$ \\
\hline Predicted value(L/s) & $49.50 \pm 0.60$ & $59.67 \pm 10.31$ & $<0.001^{* * *}$ \\
\hline$\%$ of predicted value & 4
\end{tabular}

$\mathrm{n}_{1} \mathrm{~A}=$ Total number of male subjects in study group, $\mathrm{n}_{1} \mathrm{~A}_{1}=$ male in group $\mathrm{A}_{1}$, $\mathrm{n}_{1} \mathrm{~A}_{2}=$ male in group $\mathrm{A}_{2}$, PEFR=Peak Expiratory Flow Rate, ${ }^{* *} /{ }^{* * *}=$ Significant

Table 6 Comparison of study parameters in female subjects of study group $\left(n_{2} A=24\right)$

\begin{tabular}{|c|c|c|c|}
\hline Parameters & $\begin{array}{l}\text { Group } A_{1} \\
n_{2} A_{1}=12\end{array}$ & $\begin{array}{l}\text { Group } A_{2} \\
n_{2} A_{2}=12\end{array}$ & $p$ value \\
\hline \multicolumn{4}{|l|}{ PEFR } \\
\hline Actual value(L/S) & $3.14 \pm 0.50$ & $3.56 \pm 0.48$ & $<0.048^{*}$ \\
\hline Predicted value(L/s) & $6.44 \pm 0.41$ & $6.22 \pm 0.71$ & $0.368^{\mathrm{ns}}$ \\
\hline$\%$ of predicted value & $48.58 \pm 5.96$ & $57.33 \pm 7.12$ & $<0.004^{* *}$ \\
\hline
\end{tabular}

$\mathrm{n}_{2} \mathrm{~A}=$ Total number of female subjects in study group, $\mathrm{n}_{2} \mathrm{~A}_{1}=$ female in group

$\mathrm{A}_{1}, \mathrm{n}_{2} \mathrm{~A}_{2}=$ female in group $\mathrm{A}_{2}$, PEFR=Peak Expiratory Flow Rate, ${ }^{* *} / * * *=$ Significant

\section{Discussion}

In this study peak expiratory flow rate (PEFR) was found to be significantly ( $p$ value $<0.001$ ) lower in the study group in comparison to the control group in case of both male and female. Between the two groups of AC users where AC was constantly regulated in between $18^{\circ} \mathrm{C}$ to $22^{\circ} \mathrm{C}$ and $23^{\circ} \mathrm{C}$ to $25^{\circ} \mathrm{C}$ respectively, PEFR value was significantly lower in the former group in comparison to the later one in case of both male ( $p$ value $<0.001)$ and female $(p$ value $<0.048$ and $<0.004)$. This finding is consistent to that of some researchers $[6,12]$. These findings may be explained by increased evaporation of water from the airway mucosa on contact with cold, dry air that is inhaled by the AC users. It results in mucosal cooling and hyperosmolarity that can activate TRPM8 receptors (Transient receptor potential melastatin 8) and irritant receptors that line the airway mucosa. Both of these receptors can stimulate vagal parasympathetic nerve. Hyperosmolarity of airway mucosa can also activate the mast cells. Upon activation mast cell release various inflammatory mediators like prostaglandin, leukotrienes, histamine etc. Vagal stimulation and the mediators released from the activated mast cells can directly lead to bronchoconstriction. There may be also hypersecretion of mucus, microvascular leakage, airway hypersensitivity and airway thickening. All these factors may together contribute to the bronchoconstriction and reduction in PEFR in AC users [3,13-18]. 
There may be also growth of mite allergen in AC which can cause atopic sensitization mediated by immunoglobulin E. It also enhances eosinophil activity which then release eosinophil cationic protein that is a cytotoxic molecule. It injures bronchial epithelium and bronchial mucociliary apparatus. AC can also be contaminated with various fungus and actinomycetes such as Alternaria, Penicillium etc. Exposure to these contaminants can be another possible explanation for reduced PEFR value observed in AC users $[19,20]$. These factors were not evaluated in this study.

On the other hand, a previous study showed no significant reduction in PEFR of AC users in comparison to nonusers [8]. The probable reason for the difference in the results may be the difference in the exposure time to AC, as increasing duration of exposure to air conditioner is associated with increased alternation in lung functions [21]. In the present study, subjects were exposed to AC for minimum 6 hours per day for at least 5 days per week for the past 2 to 4 years while in that study the subjects were exposed to AC for minimum 5 hours per day for at least the last 6 months [8].

From the findings of the study, it is clearly evident that air conditioner use can reduce the lung functions of AC users. But it has really become difficult to live without AC now a days as a result of increasing environmental temperature. A unique aspect of this study was to find out association between AC temperature and lung functions of AC users which could probably serve as a solution for this problem. It was found that regulation of AC at a lower temperature was associated with more reduction of PEFR in AC users. This finding clearly supports the fact that, we can minimize the negative consequence of AC use on lung functions by not regulating it at a very low level. But there is no universal cut off value for cold or low temperature. Rather it is the magnitude of downward temperature change below the mean seasonal range for a given area at which adaptive ability of the people of that area is challenged. Normal mean temperature of Dhaka, Bangladesh is $28.6^{\circ} \mathrm{C}, 27.5^{\circ} \mathrm{C}, 26^{\circ} \mathrm{C}$ and $20.2^{\circ} \mathrm{C}$ during monsoon, pre-monsoon, post monsoon and winter season respectively. There are possible harmful consequences on respiratory system when air temperature drops quickly without any gradual adaptation even for changes as low as $2^{\circ}$ to $3^{\circ} \mathrm{C}$, especially for changes greater than $5^{\circ} \mathrm{C}$. Besides it takes $60 \%$ more energy to cool a space to $72 \%$ than to cool it to $78 \%[4,1,2]$. So, there is a huge wastage of electricity. When using AC, we should keep these factors in mind and make lung function tests a part of routine health checkup for those who remain exposed to airconditioned environment for a long period of time. This will help to find out any alternation in their lung functions at an early stage and prevent development of future lung diseases by taking timely interventions.

\section{Conclusion}

Air conditioner use can significantly reduce peak expiratory flow rate of AC users. This reduction is more prominent in AC users who are exposed to a lower AC temperature as evidenced by significantly lower PEFR value of AC users who were exposed to 18 to $22^{\circ}$ Celsius AC temperature in comparison to those who were exposed to 23 to $25^{\circ} \mathrm{Celsius} \mathrm{AC}$ temperature for the same period of time.

\section{Compliance with ethical standards}

\section{Acknowledgments}

The authors thank the participants of the study and the entire Physiology department of Dhaka medical college, Dhaka, Bangladesh for their kind support.

\section{Disclosure of conflict of interest}

The authors declare no conflict of interest.

\section{Statement of ethical approval}

This study was conducted after obtaining ethical approval from research review committee and ethical review committee of Dhaka medical college, Dhaka, Bangladesh.

\section{Statement of informed consent}

Informed written consent was obtained from all individual participant involved in the study. 


\section{References}

[1] Rabby YW, Shogib MRI, Hossain ML. Analysis of temperature change in capital city of Bangladesh. J. Environ. Treat. Tech. 2015; 5(1): 55-59.

[2] Vidya G, Kumar BA, Kalpana M, Chand K. Pulmonary function tests in air conditioner users. Int. J. Med. Biomed. Res. 2014; 3(2): 75-80.

[3] D'Amato M, Molino A, Calabresc G, Cecchi L, Maesano IA, D’Amato G. The impact of cold on the respiratory tract and it's consequences to respiratory health. Clin. Transl. Allergy. 2018; 8(20): 1-8.

[4] Sabade SB, Vikhe BB, Borade NG. Pulmonary ventilation in air conditioner users in Pravara rural hospital. Pravara Med. Rev. 2013; 5(2): 4-6.

[5] Fontanari P, Burnet H, Hartmann MCZ, Jammes Y. Changes in airway resistance induced by nasal inhalation cold dry, dry or moist air in normal individuals . J. Appl. Physiol. 1996; 81(4): 1739-1743.

[6] Varu M, Kacha Y, Vegad A, Shah C, Mehta H. A comparative study of computerized spirometric parameters between air conditioner users and non air conditioner users. Int. J. Basic Appl. Physiol. 2013; 2(1): $163-166$.

[7] Moore VC. Spirometry: step by step. Breathe. 2012; 8(3): 233-239.

[8] Lavanya M, Gaikwad R. The effect of air conditioner (AC) on pulmonary functions of in young adults. Int. j. integr. Med. Sci. 2017; 4(6): 501-506.

[9] Babitha R, Rangarajan R, Muhil M, Basavarajaiah MG. Pulmonary function tests in air conditioner users. J. Clin. Diagnostic Res. 2011; 5(3): 532-535.

[10] Hulke SM, Thakare A, Patil P, Shete SA, Vaidya YP. Pulmonary functions in air conditioner users. Med. J. Dr. D.Y. Patil Vidyapeeth. 2013; 6(1): 21-24.

[11] Graham BL, Steenbruggen I, Miller MR, Barjaktarevik IZ, Cooper BG, Hall GL, Hallstrand TS, Kaminsky DA, McCarthy K, McCormack MC, Oropez CE, Rosenfeld M, Stanojevik S, Swanney MP, Thompson BR. Standarization of spirometry 2019 update. Am. J. Respir. Crit. Care Med. 2019; 200(8): 70-88.

[12] Jeelani M, Ahmed MM. Effect of air conditioner on pulmonary functions in healthy males in and around Raichur city. J. Evid. Based med. Hlthccare. 2015; 2(19): 2597-2602.

[13] Cruz AA, Togias A. Upper airway reactions to cold air. Curr. Allergy Asthma Rep. 2008; 8(1): 111-117.

[14] Xing H, Limg JX, Chen M, Johnson RD, Tominaga M, Wang CY, Gu J. TRPM8 mechanism of autonomic nerve response to cold in respiratory airway. Molecular Pain. 2008; 4(22): 1-9.

[15] Alvarado A, Arce I. Metabolic functions of the lung, disorders and associated pathologies. J. Clin. Med. Res. 2016; 8(10): 689-700.

[16] Bisgaard H. Leukotrienes and prostaglandin in asthma. Asthma. 1984; 39(1): 413-420.

[17] Empey DW. Diseases of the respiratory system. Br. Med. J. 1978; 1(1): 631-633.

[18] Nadel JA, Barnes PJ. Autonomic regulation of the airways. Ann. Rev. med. 1984; 35(1): 451-467.

[19] Kuwahara Y, Kondoh J, Tatara K, Azuma E, Nakajima T, Hasimoto M, Komachi Y. Involvement of urban living environments in atopy and enhanced eosinophil activity: potential risk factors of airway allergic symptoms. Allergy. 2001; 56(1): 224-230.

[20] Kumar P, Marier R, Leech SH. Respiratory allergies related to automobile air conditioners. N. Engl. J. Med. 1984; 311(25)16: 19-1621.

[21] Anu TE, Bahuleyan B. Analysis of dynamic pulmonary functions in airconditioned work environment. Int. J. Res. Med. Sci. 2016; 4(7): 2661-2664. 